\title{
Research Project Cost Benefits of Integrated Planning: First experiment-results
}

\author{
Iva Kovacic \\ Interdisciplinary Planning and \\ Industrial Building/e234-2 \\ Vienna University of Technology \\ iva.kovacic@tuwien.ac.at \\ DOI 10.5592/otmcj.2011.1.5 \\ Research paper
}

\author{
Michael Filzmoser \\ Institute for Management Sciences \\ Vienna University of Technology \\ Austria \\ michael.filzmoser@tuwien.ac.at
}

\author{
Stefan Faatz \\ Institute for Management \\ Sciences \\ Vienna University of Technology, \\ sabine.koeszegi@tuwien.ac.at
}

\author{
Sabine T. Koeszegi \\ Interdisciplinary Planning and \\ Industrial Building/e234-2 \\ Vienna University of Technology \\ faatz@industriebau.tuwien.ac.at
}

BEYOND THE CLASSICAL PLANNING GOALS, DESIGN PROCESSES FOR SUSTAINABLE BUILDINGS FEATURE A HIGH NUMBER OF INTEGRATED PLANNING OBJECTIVES THAT LINK ECONOMICAL, ECOLOGICAL AND SOCIO-CULTURAL ASPECTS.

With increasing demands on building performance, the number of tools for evaluation, prediction and simulation of the energy, cost and emissions efficiency is rising, as is the number of experts and the relevant professional languages applied in their planning processes. Therefore we argue that the design and planning processes for sustainable buildings represent dynamic social systems characterised by a high level of complexity. The communication and decision making mechanisms as well as the organisational structures used in the planning processes deserve particular interest as they directly influence the achievement of the desired building performance. This paper presents the interdisciplinary research project:"Cost-Benefits of Integrated Planning," (Co_Be) and the experimental study conducted within this framework. This experiment was organised as a student-competition role-play for the design of a temporary smoothie-bar in order to compare the integrated with the traditionally sequential planning practice. Preliminary qualitative and quantitative results of this experiment are provided.

\section{Keywords}

Integral design

Integral Planning

Sustainable Building

Planning Process

Analyses

\section{Introduction}

The recent building practice experiences a tremendous expansion of planning due to the raising awareness for sustainability issues. Energy efficiency, minimisation of carbon footprint and emissions, or socio-cultural aspects of human health and wellbeing, all need to be orchestrated by adequate design and planning processes. Innovative solutions are required in order to achieve "energy-plus" buildings, that are providing not only themselves but the whole neighbourhoods with energy (Blome, 2010). The EU targets 2020-20: reduction of EU greenhouse-gas emissions and primary energy use by $20 \%$, at simultaneous increase of renewable energies by $20 \%$ (ECCP, 2011) - represent only one part of institutional actions towards a low-carbon society. The future actions of the EU for climate protection and energy supply will be based on the "post-carbon society" 
guidelines, which focus on low energy (energy efficiency measurements), low carbon (renewable energies and withdrawal from fossil fuels) and low distance (short routes) (Vogel and Bieser, 2010). The concepts such as $2000 \mathrm{~W}$ society as defined by ETH Zürich (ESC 2008) and Smart City represent a step towards more holistic and integral approaches that do not singularly focus on the optimization of the performance of single building but introduce a systemic approach, in which synergies in energy production, distribution and storage are taken into account.

The introduction of these numerous requirements and planning goals significantly increases the complexity of the design process for new buildings as well as for the refurbishment of existing buildings. At the same time the scope of action in building design has been limited through numerous institutional and normative regulations concerning safety such as earthquake and fire protection codes, through introduction of Eurocode. Despite these changes: revolutionary aim-setting on building performance, especially in terms of energy efficiency on the one hand, and growing number of codes and regulations on the other, the processes for design of "new" buildings are still following the traditional paths.

The problem of raising complexity within design processes has already been recognised in the seventies and eighties, however in the realm of mechanical engineering. The Methodical design model from van den Kroonenberg, as the only model that emphasizes the execution of the process at every level of complexity was developed at the at the Faculty of Mechanical Engineering Technical University Twente for the mechanical engineers and was adopted in practice in 1974 (Zeiler and Savanovic, 2007). Yazdani and Holmes give in a case study of automotive industry an overview of design methods according to the grade of integration ranging from the sequential, design-centred, concurrent, and dynamic method, and evaluate the method-efficiency under the tripod of time-cost-quality of the output. (Yazdani and Holmes, 1999). In architecture and construction the awareness for the increasing complexity and related problems rises at later point in time: „As the complexity and the scale of design processes increased together with rising demands on these processes in terms of costs, throughout time and quality, traditional approaches to organizing and planning these processes were no longer sufficient.“ (Aken, 2003)

With the issue of sustainability, the planning and design processes are not only being challenged on the timecost-quality performance, but on a further number of planning aims such as energy and resources efficiency, minimisation of emissions and further. A significant body of literature emphasizes the importance of integrated planning for achievement of sustainability goals in built environment.

Gauzin-Müller (2002) recommends a combined the employment of traditional planning techniques with the implementation of new technologies for energy efficiency and strongly emphasizes social aspects of users' involvement in planning and future use of the building by a participatory planning method.

The life-cycle oriented "Whole-Building-Design", based on two concepts: (i) the integrated design approach and (ii) an integrated team process is proposed by Prowler (2008). On the one hand, the design or planning requirements for the building performance have to be met on a holistic level. Such a holistic model is represented by the dimensions of: accessibility, aesthetics, cost-effectiveness, functionality, historic preservation, productivity enabling (well-being of occupants), safety and sustainability (environmental performance of building elements). On the other hand there is an integrated team which includes every stakeholder of the planning process, united in a so called design charette - a collaborative brainstorming session encouraging the exchange of ideas but also enabling full understanding of all the parties as well as determining goals at the project start.

This concept has largely been adopted in the HOK (Hellmuth, Obata+Kassabaum) guideline for planning of green buildings, where a flow chart and check list for the integrated planning process is precisely outlined. (Mendler, Odell, Lazarus, 2006)

Kohler (2007) introduces an "Integrated Life Cycle Assessment", which integrates and evaluates the environmental impacts as well as initial and lifecycle costs related to gross floor area of different granulations, i.e. for macro, micro elements or construction works. This integration and evaluation is done for all relevant planning phases, beginning with programming or project development already. Such a tool requires a large amount of building related data of different granularity, in order to be applicable in every phase and by every planning stakeholder. Kohler and Lützkendorf (König et al, 2009) therefore employ a notion of integrated planning as "performance based building", with necessity of interdisciplinary (horizontal - planning profession related) and life-cycle oriented (vertical - building oriented) integration. Through implementation of building-simulation and tools for the prediction of building performance design optimization in the early planning phases is possible. Such tools, like for example integral simulation with related databases, though being desirable, however, are hardly employed at the moment due to the lack of commercial tools on the market.

Further on, building certificates such as DGNB (German Sustainability Buildings Society), BREEAM (Building Re- 
search Establishment's Environmental Assessment Method, UK) or LEED $®$ (Leadership in Energy and Environmental Design', U.S.) consider the necessity of an integrated planning method instead of traditional, sequential methods as essential for the achievement of sustainability goals, and include indicators for evaluation of the implementation of integrated planning.

\section{Paradigm change through integrated planning}

Sustainability requirements for buildings, based on a balance of economical, ecological and socio-cultural issues correspond to the Vitruvian view of the building as the composition of form, function and construction. Both concepts are based on holistic and overall concepts of balance and composition, much more than on fragmentation of singular aspects. Today's practices are affected by a scientific approach that subdivides a problem into the possibly largest amount of smaller pieces. This approach follows the idea that problem-solving can only be achieved by understanding separated sub-problems. The same principle applies to the planning process, where a large number of specialists work separately on differentiated problems, while they are required to find a holistic solution such as a building design. Overlapping of various disciplines is discouraged due to numerous reasons, like sharpening of codes and standards and meanwhile law-dominated building practices, to name only some of them, furthermore, specialisation is seen as a competitive advantage in today's markets.

Traditionally, the engineering disciplines are employing quantitative evaluation methods, traditionally based on calculation and lately on simulation methods, whereas designers and architects usually work with qualities and tend to employ an intuitive approach in problem-solving through the elimination of variants from the universe of infinite possibilities, based on training or experience. Both scientific and practice oriented approaches understand the planning process as a complicated task, that can be performed by maximisation of the experts knowledge, with an aim to find and optimise the direct relation between cause and effect. Management methods, which are based on facts (Snowden and Boone, 2007) see as the output of a problem-solving process that focuses on a complicated context as an "ideal process". The authors question this approach, and argue that the "ideal process" is different for every stakeholder (multiple perspectives).

Therefore, the holistic design and planning processes for sustainable buildings should focus on the creation of interfaces between different disciplines, instead of the development of singular expert knowledge. To use a metaphor, the picture of a planning process has to be changed from a mechanistic machine to a living organism (Wiener, 1965). Expert knowledge represents neural nodal points; integrated planning can be seen as the interconnecting network of synapses.

For the transformation from sequential planning to a more integrated practice, there are several obstacles to overcome. First, a detachment from the theoretical construct of an "ideal process" by using as much experts' knowledge as possible is necessary. Secondly, it is necessary to shift the definition of the planning process from a complicated problem to a complex problem. Through the various interactions and dependencies complex processes can adopt various different conditions. Malik (2011) argues that within complicated context, it is not possible to find a connection between cause and effect. This change in understanding of problems as complex tasks requires different methods and tools to work with. This kind of approach perceives the process as changeable and open, knowledge gaps are accepted. The according management tools are based on interaction and communication (Snowden and Boone, 2007). One major task is still the clear definition of project goals, but the way to achieve these goals is flexible and open.

Finally, a key to the transformation of planning practice lies in education. Separated education of engineering and design disciplines, as still practiced, results with fragmentation in approach to problem-solving. This fragmentation makes future planners look upon the building as a sum of its parts, instead of creating the awareness that the building is much more.

\section{CO_BE Research Project}

The Co_Be research project (COst-BEnefits analysis of integrated planning) has the aim to qualitatively and quantitatively analyse the life-cycle cost-benefits of integrated planning (IP).

This interdisciplinary project of the Vienna University of Technology (TU Wien) is funded by the Austrian Climate- and Energy Funds within the program „New Energies 2020“.

The project coordinator and initiator is Institute for Interdisciplinary Building Process Management, Department for Interdisciplinary Planning and Industrial Building, Faculty for Civil Engineering, TU Wien, further partners are the Institute for Urban Planning and Design, Department for Real Estate Development, Faculty for Architecture and Urban Planning, TU Wien and ATP Sustain Company as a partner from practice. The subsequently reported experiment was carried out as a part of this research project and in cooperation with Institute for Management Sciences, Faculty for Mechanical and Industrial Engineering. The cooperation of three different faculties allowed applying of an integrated and interdisciplinary approach within the project itself.

Based on conceptual model for integrated design and planning together 
with exploratory experimental research, this project will for the first time qualitatively and quantitatively evaluate and optimise integrated design and planning process. The final goal of the Co_Be project is the compilation of 3-module Integrated Planning Guidelines for planers, investors and policy makers. Middle-term goal is implementation of strategic steps for the integration of climate protection and energy efficiency aims within planning processes through policy but also through growing awareness among stakeholders like investors or users.

\section{Proposal for a holistic integrated planning methodology}

In order to define requirements for a holistic integrated planning methodology for design and construction of buildings this paper develops a novel model. This model consists of three main components: (i) the Building, (ii) the People (stakeholder of the planning process) and (iii) the Tools for integrated planning as a "synapse-element", linking the two former elements building and people. These tools, such as software tools, like BIM (Building Information Model), energy simulation and parametric design tools, or skills such as communication, mediation and moderation skills, connect the building (virtual or real) with ideas, knowledge and needs of people - creating the interfaces.

Through explorative experimental comparison of sequential with integrated design process, the different skills in simulated project-environments were tested. Through qualitative and quantitative evaluation of results it was possible to deduct implications for individual projects, instead of developing an ideal planning model applicable for every process.

The subsequent sections discuss the components building, people, as well as relevant tools in detail.

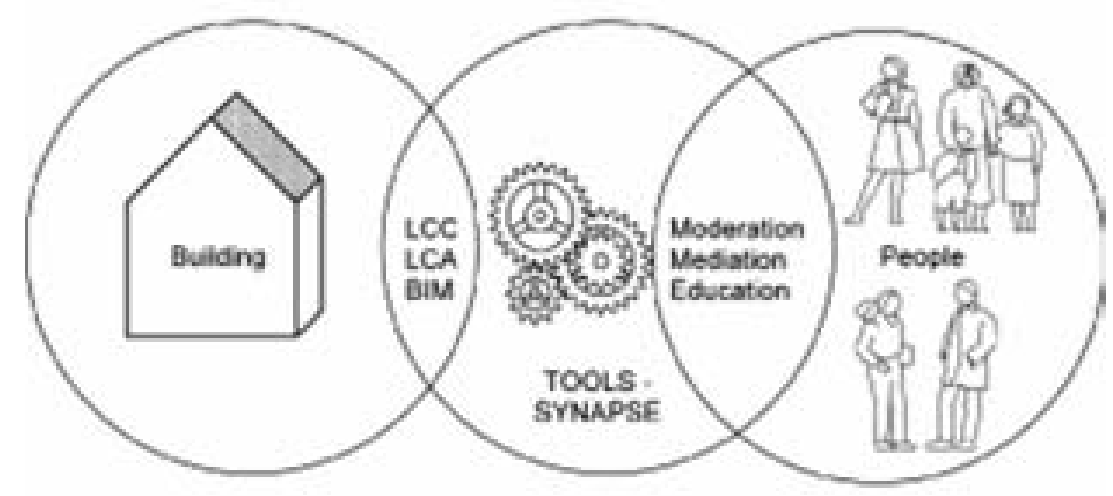

Figure 1: Relation between People, Tools and Buildings

\section{Building}

To achieve a transformation in planning practice from a fragmented process to the more integral one, a change in perception from the building as a static object towards that of a dynamic system is necessary. Life-cycle oriented, mid- and long-term strategies instead of short-term oriented planning goals are required for the realisation of sustainability objectives.

The current average life-cycle of commercial real estates has been predicted by real estate investment management companies to lay somewhere around 50 years (Schulte, 2002).

Buildings change their original use two to three times throughout this lifecycle. The consumption of energy and resources is constantly progressing over the building's life-cycle with the frequent changes of its usage. Therefore our fundamental assumption is that a building itself is not a stable and static object but rather a dynamic system.

To demonstrate the changes of buildings over time, the flow-model of material, energy, capital and information taking place throughout lifecycle of a building is proposed (Kohler, 1999). Moreover, different layers of the building can be identified, according to their existence, which again experience different temporal changes: rhythms, cycles and phases. Brand (1994) proposes a “6s" building model, consisting of slow and long-lasting layers like site (eternal) and primary structure (50 - 60 years), and fast and changing elements of short life such as skin (20 years), services (7-15 years), space plan (3 years) and stuff-mobilia (monthly).

The ambivalent nature of a building as composition of "tangibles" - quantities and "intangibles"- qualities causes problems for the development of both clearly defined planning goals as well as performance evaluation strategies. As tangible data a building's quantitative characteristics concerning the ecologic and economic issues can be defined. The intangible data is expressed through quantitative characteristics such as formal, cultural and functional aspects.

A Parametric model for performance evaluation can be based on a system of sustainability indicators (Kovacic, 2007), that describe the building performance in terms of:

- ecology: eco-efficiency, minimisation of land consumption, soil pollution, $\mathrm{CO}_{2}$ emissions, primary energy consumption, substitution of fossil energy sources through regenerative energy sources, innovative technologies in energy efficiency

- economy: construction costs, investments, yields, LCC (heating and cooling, ventilation, lightning, maintenance, inspection and service), flexibility for further use

- socio-cultural aspects: thermal comfort, human health, relationship to the landscape, barrier free building, creation of liveable urban 
identity, accessibility of workplace residence quality for all ages, consideration of balanced income structure regarding working places, integration foreign co-citizens,

\section{People}

As discussed above, an integrated planning process is open and flexible and can react to changes in the complex environment of the process. In the past, the majority of scientific and practical knowledge creation was achieved by monitoring the processes detached from the involved people. To understand complex process-conditions, it is crucial to involve the people that create these processes. It is not possible to handle these conditions only by measurable data and hard facts, qualitative soft facts become more relevant and have to be integrated in the working process with complex systems to create a more adequate process picture (Vester, 2002). This approach calls for the understanding of the planning process as part of a social system.

In complex environments possible incidents cannot be anticipated easily by the involved people who create an atmosphere of uncertainty. The sociologist Niklas Luhmann (1996) showed that complexity in a social system can be reduced by trust. For example, a planning meeting where all participants have to think about the "hidden agendas" of the other meeting attendees has significant more complexity than a meeting that is based on trust where declarations can be made and accepted without additional cognitive activities. Luhmann also shows that differences between a collective of single individuals and a connected social system manifest in their communication. Additionally, the demand for social interaction by communication increases with the complexity of the process (Pawlowsky and Mistele, 2008), which is also a major aspect due to the increasing planning process complexity discussed above. Orpen (1997) moreover found in an empirical study, with a sample of 135 managers from 21 different firms from a variety of industries, that the quality of communication has a major impact on the satisfaction and the motivation of managers. It is obvious that motivation and satisfaction of employees has an impact on the quality of a planning process. As a conclusion it can be stated that one major aspect for the performance of a planning process is the way people interact in the process.

\section{Tools}

The Tools for integrated planning: the "synapse-element" links the elements of Building and People. The Tools can address quantities or qualities of a building, and can be employed simultaneously or in different stages of planning process.

To quantitative the Tools for prediction or evaluation of building performance count different software-tools, procedures or computer-simulations.

Building Information Modelling (BIM) is a set of interacting policies, processes and technologies generating a "methodology to manage the essential building design and project data in digital format throughout the building's life-cycle" (Succar, 2009).

Software such as Autodesk's Revit offers a high level of integration of differently granulated and structured information in one single model and the possibility for simultaneous work of different disciplines such as architecture, structural engineering, building services etc. Through additional modules energy simulation and life-cycle assessment is possible.

The life-cycle cost calculation tools are more rare. In Central Europe, LEGEPSoftware (Kohler, Lützkendorf, 2002) counts currently to the most reliable ones, even though often criticised for not being suitable for the cost estimation and variant-evaluation in the early planning phases.
Numerous emerging international and national building certificates offer systems for the evaluation of different aspects of sustainability and try to promote a holistic view on the building performance. Their extensive catalogues of indicators moreover provide a source for visualisation of quantifiable planning goals for clients in early planning phases.

To enhance and develop the quality of project participants' interaction and of the aim setting for building qualities, methods and recent findings from sociological and medical sciences can help to improve today's planning processes. Knowledge gained in relatively new sciences like for example neurosciences, with its non-invasive examination methods, resulted in a new and differentiated understanding of human behaviours and could be informative for the conception of integrated planning processes. To improve the necessary communicational skills and implement this knowledge new ways of (continuing) education must be implemented. It is important to consider the interaction of people in educational programs. A separation into subjects where each student has to improve as a single individual hinders rather than supports the development of social competences. Another required skill is the ability to reflect the own behaviour. This is the basis for social learning, and the development of social skills. Educational programs have to provide space for the participants to rethink their own assumptions and behaviour (Schön D.A., 1983).

An integral planning process can handle more complexity but also requires much more coordination between the participants compared to a sequential approach. This also affects the leadership of integral process leaders. In an integrated team the responsibilities are more decentralised which increases the self confidence of all process participants. The leadership characteristic is 
based on sense. Hüther (2007) shows, that the search for sense is a necessity resulting from the structure and operation mode of the human brain. Strict hierarchical structures are counterproductive for a team based and self organising process. The role of the process leader is characterised by coordinating activities. These open and variable boundary conditions also have to be considered in the contracts. Today's contracts often focus on the clear detachment of responsibilities this disables team based problem solving processes. The overlapping interests of different stakeholders are the major issue that have to be considered to ensure a holistic approach. The social competence of the process participants and the creation of interaction between the involved people is therefore one of the major opportunities to improve today's planning processes.

The tools to advance interaction and communication qualities between people are various. The mentioned integrated process approach demands sense of community. Disciplines like mediation or the implementation of mediative know-how focuse on this attitude level. As the core business of mediation is the management and resolution of conflicts its approaches can be learned and implemented in daily communication. The main characteristic is the move from positions to interests. For the performance of the process an interest based communication can be crucial to prevent escalating conflicts and to ensure effective teamwork.

Another major team development effect can be initiated by well designed kick-off events. These events can bring people closer together and create a common picture of the task of the team. Additionally the level of trust can be increased which reduces process complexity as discussed above. An appropriately arranged kick-off event initiates the so called "forming" phase of the team development process (Tuckman, 1965).
According to the size of the project and the number of process participants it can be effective to assign a person responsible for the designing and guiding of the process communication. This person can moderate relevant project meetings and is the confidant in case of conflicts. For this person to be impartial it is crucial that it is only reliable for the process communication and has no other tasks, otherwise the guiding of communication can be in conflict with her own process interests.

There are various other tools coming from different disciplines like moderation, group dynamics or psychology. Due to the openness and flexibility of integrated planning process, the application of social interactive methods is situative.

\section{Laboratory Experiment}

To evaluate the effects of the integral design and planning methodology and to compare them to those of a traditionally sequential planning process, we designed and conducted a laboratory experiment. This first exploratory study of the integral and sequential planning, was carried out with students in order to obtain large amount of qualitative and quantitative data and due to the long duration of experiment. In order to verify the results, a workshop with practitioners will be held, as the next step.

The experiment was set up as a student competition in a university course on building process management for students in fourth semester of their civil engineering study together with higher semester architecture students. Besides credit points for the course, motivation of participants was induced by monetary prices for the three best performing student teams (in each treatment) according to a jury evaluation of the results. Planning teams consisted of four roles: (i) an architect, (ii) a civil engineer for structure and building services, (iii) a client and (iv) a business advisor. The planning task was to de- sign smoothie-bar based on renewable energies (solar gains) and resources (wood). We decided for a laboratory experiment with student participants to gather a large number of observations of planning processes and their results for which we can control potential influencing factors so that differences can be assigned directly to the different planning methodology.

To ensure the comparability of the results the information of the planning teams was held constant by providing the same materials (handouts, product information sheets, tables for calculation of solar gains, energy consumption, etc.) to all teams and forbidding the use of internet and electronic devices. To generate the experimental conditions we established two treatments: (i) sequential planning (SP) and (ii) integral planning (IP).

A total of 160 students participated in the experiments. They were assigned to one of the two treatments (each consisting of 80 participants) according to the subsequently described procedure to control for a equal distribution of demographic characteristics, education and professional experience across the treatments, within each treatment the students were assigned randomly to one of the 20 teams and one of the four roles. The distribution of the students into the two treatments was based on information, collected by a questionnaire before the experiment, about their demographics (age, gender), education (polytechnic graduation, semester of studies) and full time equivalent (FTE) professional experience in months. We identified participants with as similar as possible characteristics in these measures and then assigned one of them to the IP and the other one to the SP treatment randomly by coin toss. The average values for these measures for all participants and for the members of each treatment are presented in Table 1. This table also presents the test statistics and significance values for the statistical tests - t-test to test 
for differences in the numeric variables age, semester of studies or FTE of professional experience, and $x^{2}$-tests for the categorical variables gender, polytechnic graduation - applied to control the effectiveness of the treatment assignment procedure described above. business advisors may be contacted - it is likely that she will change the concept significantly since her superior knowledge of the core-business compared to the remaining team members. During the planning process the participants had to record their work-
In all four subjective satisfaction criteria the IP achieved the better results. Integral planers were more satisfied with the planning process (average satisfaction with the planning process: 4.12 vs. 3.96$)$ and also with the resulting design (average satisfaction with

\begin{tabular}{|l|l|l|l|l|l|l|}
\hline measure & all $(\mathrm{n}=160)$ & $\mathrm{IP}(\mathrm{n}=80)$ & $\mathrm{SP}(\mathrm{n}=80)$ & Test statistic & df & $\mathrm{p}$-value \\
\hline age $(\varnothing)$ & 22.87 & 22.58 & 23.16 & $\mathrm{t}=-0,91$ & 157.77 & 0.3631 \\
\hline $\begin{array}{l}\text { gender (femal) } \\
\text { polytechnic graduation }\end{array}$ & $\mathbf{2 9 . 3 8 \%}$ & $30.00 \%$ & $28.75 \%$ & $\mathrm{x}^{2}=0.00$ & 1.00 & 1.0000 \\
\hline semester of studies & 5.65 & $50.00 \%$ & $47.50 \%$ & $\mathrm{x}^{2}=0.03$ & 1.00 & 0.8743 \\
\hline FTE experience (months) & 7.88 & 5.51 & 5.79 & $\mathrm{t}=-0,32$ & 150.81 & 0.7484 \\
\hline
\end{tabular}

Table 1: Demographics, education and professional experience of the participants in the experiment (overall and per treatment)

The experiments took one whole day (8 a.m. to 4 p.m.). After a general introduction and an individual briefing for each role the IP teams were grouped together in working booths, and worked on the assignment simultaneously (see Figure 3). In the SP treatment, the roles, rather than the teams were grouped together, i.e. all clients, architects, civil engineers and business advisors were situated in separate rooms (see Figure 2). Coordination and communication was restricted to pair wise interactions to guarantee a sequential planning process of the SP teams.

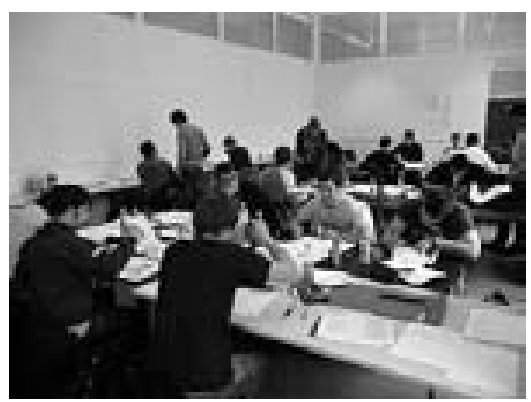

Figure 2: Group of "civil engineers" performing sequential planning

In both treatments the clients in a first step instruct their architects, only after the pre-design is satisfactory the engineers may be contacted by the clients. After completion of the engineering and structural concept, which has to be approved by the architects, the

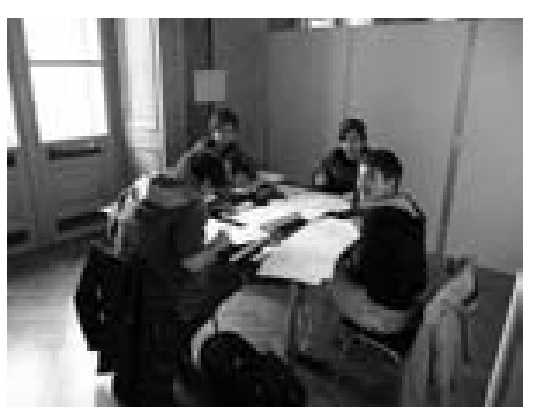

Figure 3: Team of "architect", "client, "civil engineer" and "business advisor”, performing integrated planning

load, conflicts and how much time they spent on which tasks. At the end of the experiment participants answered a questionnaire concerning their satisfaction with the process, outcome, cooperation and team functionality (each construct measured by four items on a Likert scale from 1 - very bad - to 5 - very good).

\section{Preliminary Results}

Our first analyses confirm a good operationalization of the four constructs evaluated in the post experiment questionnaire: (i) satisfaction with process, (ii) satisfaction with outcome, (iii) satisfaction with cooperation, and (iv) satisfaction with team functionality (Cronbach Alpha 0.78, 0.92, 0,88 and 0,88, respectively). the planning outcome: 3.90 vs. 3.71). However, these differences are not statistically significant $(p=0.1212$ and $p=0.1855$ respectively according to a $\mathrm{t}$-Test of equality of means). Figure 4 illustrates the participants' satisfaction with the planning process and outcomes in the two treatments by box plots.

Concerning the satisfaction with the cooperation and communication of team members during the planning process again integral planer are more satisfied than their sequentially planning colleagues (average satisfaction with the cooperation: 4.52 vs. 3.75 ), which is also true for the satisfaction with the functioning of the team (average satisfaction with team functioning: 4.44 vs. 3.88 ). These differences in the later two subjective evaluation criteria is statistically significant ( $p<0.001$ for both according to a t-Test of equality of means). These differences in satisfaction with cooperation and team functioning between integral and sequential planning are visualized by box plots in Figure 5.

At the award event additional information from the participants was obtained by means of a small feedback workshop, in order to obtain the quali- 
Satisfaction with Planning Process

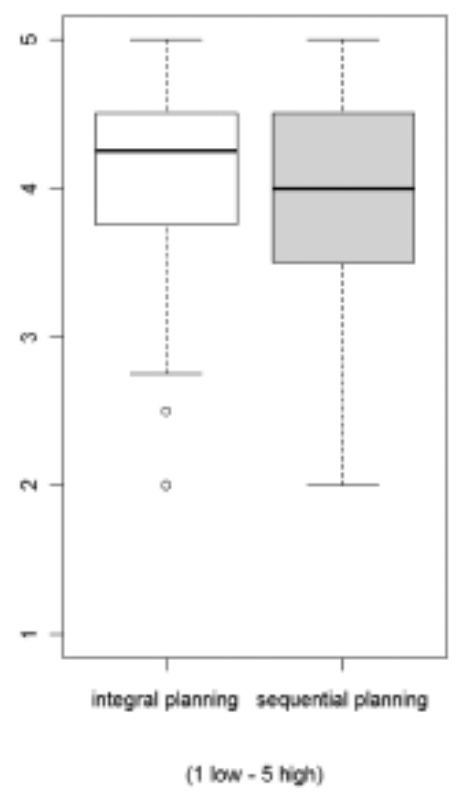

Satsifaction with Planning Outcome

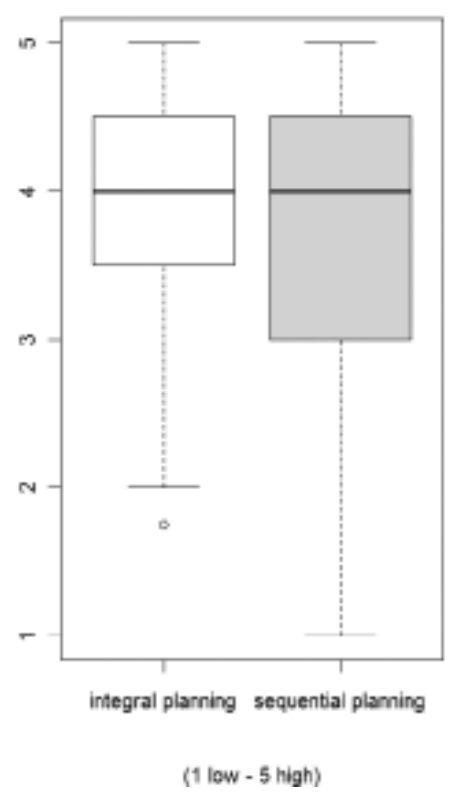

Figure 4: Box plots of the participants' satisfaction with the planning process and outcome

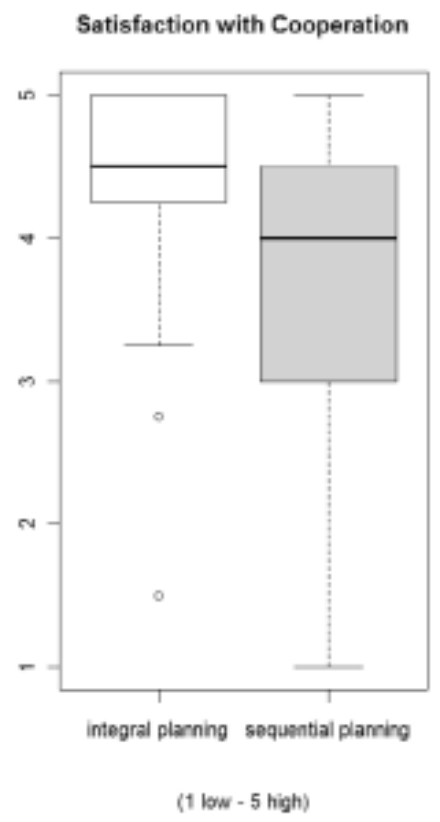

Satisfaction with Team Functioning

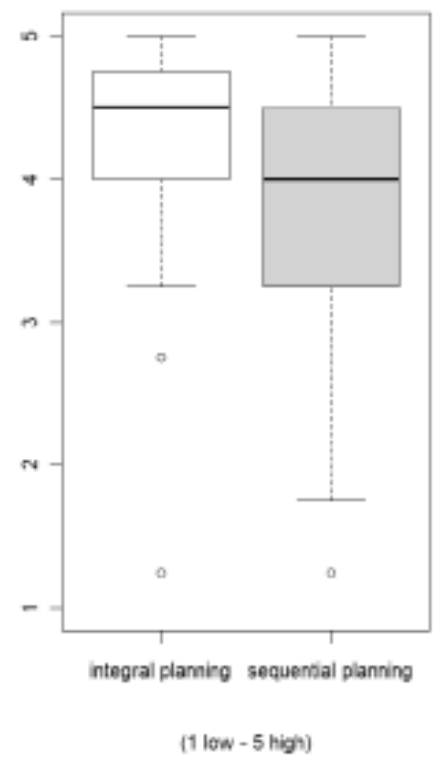

Figure 5: Box plot of the participants' satisfaction with the cooperation and team functioning

tative information on advantages and disadvantages of sequential and integral planning processes. This was done to blend the results from the above mentioned quantitative analyses with qualitative information. Students were assigned to groups consisting of two members of the IP and two members of the SP treatment in the experiment and asked to name the advantages and disadvantages of integrated and sequential planning and to identify the main differences they experienced (qualitative results of this workshop are summarized in Table 2).

The advantages of sequential planning are above all seen in the possibility to focus on the own tasks ("more concentration on own task", "focusing"), selfdetermination ("independent working is possible"). The list of disadvantages experienced in sequential planning was longer including communication problems ("long communication distances", "ambiguities in communication", "bad information flow", "bad communication"), unequal distribution of the workload over roles or time ("stress", "lot of work for the client") and problems in cooperation in a sequential planning process ("no influence on design proposals of other disciplines", "common solution finding is not possible").

As advantages of integral planning students mentioned the time saving ("Time saving" and "takes longer" as a disadvantage of sequential planning"), teamwork ("you are not alone", "team spirit", "teamwork functioned well") better communication ("good information flow", "conflict solving possible", "feedback") and better outcomes ("melting of ideas", "rounder result"). Students found the conflict level in the integral planning process to be a negative aspect ("less peace", “differences in opinion"), furthermore too much integration may also be conceived negative ("difficult to find a common language", "everybody is meddling in the discipline of the other").

The feedback of the students from this workshop corresponds to the results of our analyses above. As both planning processes have their pros and cons there might not be immediate differences in the satisfaction with the process itself and its outcome. However, the communication and team functionality is better for integrated planning teams and the student feedback throws light on the causes of these differences. 


\begin{tabular}{|l|l|l|}
\hline & Integrated planning & Sequential planning \\
\hline Pros & $\begin{array}{l}\text { - time saving } \\
\text { - teamwork } \\
\text { - better communication } \\
\text { - better outcomes }\end{array}$ & $\begin{array}{l}\text { - focus on the own task } \\
\text { - self-determination }\end{array}$ \\
\hline Cons & $\begin{array}{l}\text { - higher conflict potential } \\
\text { - 'over'-integration }\end{array}$ & $\begin{array}{l}\text { - communication problems } \\
\text { - unequal workload } \\
\text { - cooperation problems }\end{array}$ \\
\hline
\end{tabular}

Table 2: Summary of the workshop on pros and cons of integral and sequential planning

In general IP is seen by the students as more time efficient and offering more time for discussion (which also might lead to conflicts). SP consumes more time for coordinating and managing the process and also for communication loops as direct feedback in not possible. This leads to the conclusion that the resource time is more efficiently used in the integral planning process so that more time can be used on solving the design problem as not so much time needs to be spent on organizing the planning process or compensating its deficiencies. We expect that the detailed analyses of the planning processes on the basis of the records on conflict level, workload and task duration and distribution, which are currently performed, provide further insights about the detailed differences of the sequential and integral building planning process.

\section{Conclusion}

The discourse on rising complexity of the planning process caused by the increased demands of sustainable, energy efficient buildings, shows that a transition from traditional, fragmented planning practice towards a more integrated practice is necessary.

The transformation of the traditional design and planning process requires on the one hand a change in perception of buildings themselves - a lifecycle oriented approach enables the development of long term strategies in perceiving buildings as dynamical systems rather than static objects. On the other hand, the stakeholders of the planning process, which are not only planners and experts but also users and neighbours, need the development of new techniques for successful communication, moderation and organisation of the planning process in order to achieve their common goal of a sustainable building which is be perceived as satisfactory from their multiple perspectives.

We argue, that for achievement of both of these issues an integrated planning approach is necessary. For realisation of highly complex energy producing buildings appropriate modelling tools and expert knowledge is necessary on the one hand, on the other hand communicational and organisational skills and tools are necessary for achievement of common aims and of a building that is more than just a sum of the parts.

In order to develop a methodology for integrated design and planning, a two component model of building and people was proposed, with the interface of tools for integrated planning which builds the synapse between the two former components. The tools themselves contribute to the transformation from fragmentation towards integranodal points of expert knowledge.

Our qualitative analyses of student feedback revealed that integral planning is perceived as more time efficient. However the available time need not be used in productive problem-solving necessarily but could also be spent on conflicts caused by the interfering of realms of different disciplines. This highlights the necessity to develop new skills for the successful tion, and close the gaps between the functioning of integrated teams. However, despite these challenges the integrated planning process is perceived as significantly more satisfactory concerning the communication, cooperation and team functionality compared to its traditionally sequential alternative. As advantage of IP also a building of team spirit was identified, that resulted with an overall rounder result through melting of ideas - which again underlines the importance of linking instead of fragmentation.

\section{Acknowledgment}

The research presented in this paper is supported by funds from FFG (Neue Energien 2020: “Co_BE: Costs Benefits of Integrated Planning”)

\section{REFERENCES}

Aken J.E. van (2003) „On the design of design processes in architecture and engineering: technological rules and the principle of minimal specification“, working paper 03.08, Eindhoven Centre for Innovation Studies, June 2003, Technische Universiteit Eindhoven, June 2003

Blome, B. (2010), „Bauen für die Zukunft Das Plus-Energie Haus“, in: Energie und Umweltzentrum (Publ.): Tagungsband 3. Effizienztagung Bauen und Modernisieren,

10.-20.November 2010, Hannover

Brand, S. (1994), How Buildings Learn, USA: Penguin Books, USA

DGNB (2008), „Das Deutsche Gütesiegel Nachhaltiges Bauen: AufbauAnwendung-Kriterien“, http://www. dgnb.de/ (accessed 30 of May 2011) ESC (2008): „Energiestrategie für die ETH Zürich“, working paper, Energy Science Center,

ETH Zürich, Zürich

ECCP(2011), European Climate Change Program available at: http://ec.europa.eu/ clima/policies/package/index_en.htm (accessed 30 of May 2011)

Gauzin-Müller D. (2002), Nachhaltigkeit in Architektur und Städtebau, Birkhäuser, Basel-Berlin Boston, pp. 99 Hüther, G. (2007), „Die neurobiologischen 
Grundlagen der Suche des Menschen nach Sinn“, Persönlichkeitsstörung: Theorie und Therapie, Vol.11: No.4, pp. 219-228

Kovacic, I. (2007), "Building performance evaluation on "dynamical building" model -towards strategy for sustainable planning”, in: M. Schrenk (ed.) “REAL CORP 2007 - To plan is not enough, 12th International Conference on Urban Planning and Regional Development in the Information Society", CORP, Vienna

Kohler, N., Barth, B., Heitz, S., Hermann, M. (1999) : „Life Cycle Models of Buildings - a New Approach“, ifib- Institut für Industrielle Bauproduktion, Universität Karlsruhe, D-76128 Karlsruhe

Kohler, N., (2007), “ Zukunftsfähige Gebäude“, in: archplus, 184, pp.

König H., Kohler N., Kreißig J., Lützkendorf T., (2009), Lebenszyklusanalyse in der Gebäudeplanung, Detail Green Books, München

Kohler N., Lützkendorf T., (2002), „Integrated life cycle analysis“, Building Research and Information, Vol. 30, Issue 5, pp. 338-348

LEGEP, http://www.legep-software.de/, accessed 30 May 2011

Luhmann, N., 1996, Social Systems, Stanford University Press, Stanford, California

Malik, F., 2011, Strategie: Navigieren in der Komplexität der Neuen Welt, Campus Verlag GmbH, Frankfurt am Main Mendler, S., Odell, W., Lazarus, M.A.,
(2006), The HOK guidebook to Sustainable Design, John Wiley\&Sons Hoboken, New Jersey, U.S.A

Orpen, C., 1997, "The Interactive Effects of Communication Quality and Job Involvement on Managerial Job Satisfaction and Work Motivation", The Journal of Psychology: Interdiciplinary and Applied, 131, 5, pp. 519- 522

Pawlowsky, P. and P. Mistele, 2008, Hochleistungsmanagement: Leistungspotentiale in Organisationen gezielt fördern, Betriebswirtschaftlicher Verlag Dr. Th.Gabler, Wiesbaden

Prowler, D., (2008), “Whole Building Design”, National Institute of Building Sciences, Washington

REVIT http://www.autodesk. de/adsk/servlet/pc/ index id $=14644879$ \& sitelD $=403786$ (accessed 30 May 2011)

Schön, D.A., 1982, The Reflective Practitioner: How Professionals Think in Action, Arena Verlag, Michigan

Schulte, K.-W. et al, 2002. „Grundlagen der Projektentwicklung aus immobilienwirtschaftlicher Sicht“, Schulte, K.-W. und Bone-Winkel S. (Eds.) Handbuch ImmobilienProjektentwicklung, Immobilien Informationsverlag, Rudolf Müller GmbH, Köln, pp.

Succar, B. (2009): Building information modelling framework: $A$ research and delivery foundation for industry stakeholders, Automation in Construction, Vol. 18 pp. 357-375

Snowden, D.J. and M.E. Boone, 2007, "Entscheiden in chaotischen Zeiten", Harvard Business manager, dez.07, pg. 28-42

Vester, F., 2002, Die Kunst vernetzt zu denken, Ideen und Werkzeuge für einen neuen Umgang mit Komplexität, Deutscher Taschenbuchverlag, München

Vogel T., Bieser H., (2010) "smart cities “, Klima-und Energiefonds Schwerpunkt 2011, Wien

Wiener, N., 1965, Cybernetics, Second Edition: or the Control and Communication in the Animal and the Machine, MIT Press, Massachusetts

Yazdani B., Holmes. C. (1999), "Four models of design defnition: sequential, design centered, concurrent and dynamic", Journal of Engineering Design, 10(1), pp. 25-37

Zeiler W., Savanovic P. (2009) „Integral design workshops: Organization, structure and testing“, Working paper, Technische Universiteit Eindhoven, Eindhoven, The Netherlands 